\title{
Whitening Effect of Watersoluble Royal Jelly from South Korea
}

\author{
Sang Mi Han*, Jung Min Kim, In Phyo Hong, Soon Ok Woo, Se Gun Kim, \\ Hye Ri Jang, Kwan Kyu Park ${ }^{1}$, and Sok Cheon Pak ${ }^{2}$ \\ Department of Agricultural Biology, National Academy of Agricultural Science, Wanju 55365, Korea \\ ${ }^{1}$ Catholic University of Daegu School of Medicine, Daegu 42472, Korea \\ ${ }^{2}$ School of Biomedical Sciences, Charles Sturt University, Bathurst, NSW 2795, Australia
}

\begin{abstract}
Royal jelly has been widely used as a health supplement worldwide. However, royal jelly has been implicated in allergic reactions, and we developed a water-soluble royal jelly (WSRJ) without the allergy inducing protein. In this study, we aimed to identify the anti-melanogenic efficacy of WSRJ. B16F1 melanoma cells were first treated with $10 \mathrm{nM} \alpha$-melanocyte stimulating hormone $(\alpha-\mathrm{MSH})$ and then with various doses of WSRJ. In addition, we investigated the mRNA and protein expression of melanogenesis-related genes such as tyrosinase, tyrosinase related protein-1 (TRP-1) and TRP-2 by reverse transcription-polymerase chain reaction and western blotting. WSRJ directly inhibited tyrosinase and cellular tyrosinase activity, which decreased melanin synthesis in $\alpha-\mathrm{MSH}$ stimulated B16F1 melanoma cells a level comparable to that observed with arbutin. WSRJ decreased the mRNA and protein expressions of tyrosinase, TRP-1, and TRP-2, which was comparable to that observed with arbutin. WSRJ has strong anti-melanogenic activity, which invoice direct inhibition of tyrosinase enzyme activity and suppression of expression of melanogenesis related genes. Results from this study suggests that WSRJ is a potential candidate for the treatment of skin pigmentation.
\end{abstract}

Keywords: royal jelly, water-soluble royal jelly, $\alpha-\mathrm{MSH}$, tyrosinase, TRP-1, TRP-2

Received August 11, 2015; Revised September 24, 2015; Accepted October 1, 2015

\section{Introduction}

Melanogenesis is a biosynthetic pathway for melanin synthesis from melanocytes located in the lowest layer of epidermis in human skin (Yokota et al., 1998). Melanin is synthesized in melanosomes which are specialized pigment organelles in melanocytes. Melanin plays an important role in protecting the skin and hair from ultraviolet (UV) irradiation. However, excessive exposure to UV radiation causes hyperpigmentation disorders such as melasma, nevus, freckles and solar lentigenes (Urabe et al., 1998). When the skin is exposed to UV radiation, $\alpha$-melanocyte stimulating hormone ( $\alpha-\mathrm{MSH})$ is secreted, which binds to melanocortin 1 receptor (MC1R). MC1R is mainly regulated by melanogenic enzymes including tyrosinase, tyrosinase related protein (TRP)-1 and TRP-2 (Hearing, 1999). Tyrosinase is a rate-limiting enzyme involved in melanin production that catalyzes the hydroxylation of $\mathrm{L}$ tyrosine to L-3,4-dihydroxyphenylalanine (L-DOPA) and

\footnotetext{
*Corresponding author: Sang Mi Han, Department of Agricultural Biology, National Academy of Agricultural Science, Wanju 55365, Korea. Tel: 82-63-238-2896, E-mail: sangmih@korea.kr
}

the conversion of L-DOPA to dopaquinone (Urabe et al., 1998). Dopaquinone can be converted to a semi-stable dopachrome in the absence of sulfur-containing compounds. TRP-2 catalyzes the conversion of dopachrome to 5,6dihydroxyindole-carboxylic acid and TRP-1 oxidizes 5,6dihydroxyindole-carboxylic acid to indole-5,6-quinone carboxylic acid, ultimately leading to melanin synthesis (Hearing and Tsukamoto, 1991; Solano et al., 2006). Hence, down-regulation in these enzymes leads to a decrease of melanin synthesis.

Royal jelly (RJ) is secreted from the hypopharyngeal and mandibular glands of worker honeybees, and is well known to be essential for the growth of the queen honeybee (Jozef, 2001). RJ is widely marketed and used in various health promoting products including cosmetics, food supplements, beverages, and commercial medical products for all age groups (FAO, 2007). RJ is composed of water, protein, total sugars, lipids, vitamins, free amino acids, and 10-hydroxy-2-decenoic acid (10-HDA). RJ has been reported to confer a number of physiological and pharmacological benefits including anti-tumor (Tolanai and Morgan, 1962), anti-hypertensive (Tokunaga et al., 2004), anti-inflammatory (Kohno et al., 2004), wound

(9)This is an open access article distributed under the terms of the Creative Commons Attribution Non-Commercial License (http://creativecommons.org/licences/ by-nc/3.0) which permits unrestricted non-commercial use, distribution, and reproduction in any medium, provided the original wokr is properly cited. 
healing (Park et al., 2012), and anti-photoaging (Park et al., 2011) properties in vivo and in vitro. We demonstrated in a previous study that RJ reduces melanin synthesis by down-regulating tyrosinase mRNA transcription (Han et al., 2011)

However, RJ has been linked to allergic contact dermatitis, acute asthma and anaphylaxis in countries with high consumption of RJ (Rosmilah et al., 2008). Several studies have reported that RJ-sensitive subjects possess immunoglobulin $\mathrm{E}$ ( $\mathrm{IgE}$ ) binding proteins between 47 and 55 kilo Daltons and these have been recognized as the major allergens of RJ (Rosmilah et al., 2008). In our preliminary data, we confirmed this effect in water-soluble RJ (WSRJ), wherein the allergens had been eliminated (Kim et al., 2013). We also reported that the only difference between the components of RJ and those of WSRJ is the presence of allergic proteins in the former.

To our knowledge, there are no reports on the inhibitory effects of WSRJ on melanogenesis regulated by melanogenic enzymes. Therefore, in the present study we investigated the potential anti-melanogenic effects of WSRJ. To determine the effects of WSRJ on melanogenesis, we evaluated tyrosinase activity and melanin levels in $\alpha$-MSHstimulated B16F1 melanoma cells. In addition, we explored the possible mechanisms of WSRJ by examining the regulation of mRNA and the levels of tyrosinase, TRP-1 and TRP-2 proteins.

\section{Materials and Methods}

\section{Reagents}

Dulbecco's Modified Eagle's Medium, fetal bovine serum and penicillin/streptomycin $(100 \mathrm{IU} / 50 \mu \mathrm{g} / \mathrm{mL})$ were obtained from Invitrogen (Grand Island, USA). Antibodies against tyrosinase, TRP-1, TRP-2 and $\beta$-actin were purchased from Abcam (Cambridge, USA). All other chemicals including 3-(4,5-dimethylthiazol-2-yl)-2,5-diphenyltetrazolium bromide, $\alpha-\mathrm{MSH}$, dimethyl sulfoxide (DMSO), mushroom tyrosinase and L-DOPA were purchased from Sigma-Aldrich (USA).

\section{Preparation of WSRJ}

Fresh royal jelly of Apis mellifera L. was collected from Inje County, Gangwon Province, Korea. Upon receipt, it was stored at $-20^{\circ} \mathrm{C}$ until used. Lyophilized RJ was extracted twice with $70 \%$ ethanol. The supernatants were enriched and lyophilized for $48 \mathrm{~h}$. Lyophilized RJ powder was dissolved in distilled water by stirring for $1 \mathrm{~h}$ and the $\mathrm{pH}$ was neutralized to 7.4 by sodium hydroxide. The ext- racts were re-lyophilized and kept at $-20^{\circ} \mathrm{C}$ until use.

\section{Cell culture and WSRJ treatment}

B16F1 melanoma cells purchased from the Korean Cell Line Bank (Korea) were cultured in Dulbecco's Modified Eagle's Medium supplemented with $10 \%$ (v/v) fetal bovine serum and $1 \%$ penicillin/streptomycin at $37^{\circ} \mathrm{C}$ under $5 \% \mathrm{CO}_{2}$ in air atmosphere. B16F1 melanoma cells were seeded at a density of $5 \times 10^{3}$ cells/well in 6-well plates. After $24 \mathrm{~h}$, the cells were cultured in fresh media supplemented with $10 \mathrm{nM} \alpha-\mathrm{MSH}$ for $48 \mathrm{~h}$, and then treated with various doses of WSRJ. After $24 \mathrm{~h}$, the cells were harvested and used for various assays.

\section{Cell viability assay}

After incubation, the cultured medium was replaced with $50 \mu \mathrm{L}$ MTT solution $(1 \mathrm{mg} / \mathrm{mL}$ in PBS) in each well. After incubation at $37^{\circ} \mathrm{C}$ for $4 \mathrm{~h}$, the solution was carefully removed, and $100 \mu \mathrm{L}$ DMSO was added. The absorbance of each well was measured at $570 \mathrm{~nm}$ using a microplate reader (Bio-Tek Instruments, USA).

\section{Melanin content assay}

After cell cultivation, the cells were washed with PBS and harvested by trypsinization. The cell pellets were homogenized in lysis buffer containing $50 \mathrm{mM}$ sodium phosphate, $1 \%$ Triton X-100 and $2 \mathrm{mM}$ phenylmethylsulfonyl fluoride (PMSF). After centrifugation at 14,000 rpm for $15 \mathrm{~min}$, the melanin pellets were dissolved in 200 $\mu \mathrm{L} 1 \mathrm{M} \mathrm{NaOH}$ containing $10 \%$ DMSO at $80^{\circ} \mathrm{C}$ for $1 \mathrm{~h}$. Absorbance was measured at $405 \mathrm{~nm}$ using a microplate reader. The melanin content was determined using an authentic standard of synthetic melanin. Protein content was determined using a Bradford assay with bovine serum albumin (BSA) as the protein standard.

\section{Mushroom tyrosinase activity assay}

An in vitro mushroom tyrosinase inhibition assay was performed as described previously by Lee et al. (2010) with slight modifications. We added $120 \mu \mathrm{L}$ of $8.3 \mathrm{mM}$ L-DOPA in $80 \mathrm{mM}$ phosphate buffer ( $\mathrm{pH} 6.8$ ) to each well of a 96-well plate and $40 \mu \mathrm{L}$ of the same buffer or WSRJ at various doses, followed by $40 \mu \mathrm{L}$ of $125 \mathrm{U}$ mushroom tyrosinase in $80 \mathrm{mM}$ phosphate buffer. After $30 \mathrm{~min}$ incubation at $37^{\circ} \mathrm{C}$, absorbance was measured at $490 \mathrm{~nm}$ using a microplate reader.

\section{Tyrosinase activity assay}

A tyrosinase activity assay was performed according to 
the method described previously with slight modifications (Lee et al., 2010). B16F1 cells were lysed in $20 \mathrm{mM}$ sodium phosphate (pH 6.8), 1\% Triton X-100 and $1 \mathrm{mM}$ PMSF, and centrifuged at $14,000 \mathrm{rpm}$ for $15 \mathrm{~min}$. The protein content of each supernatant was determined using the Bradford assay with BSA as the protein standard. Tyrosinase activity was determined in a reaction mixture $(1 \mathrm{~mL})$ containing $50 \mathrm{mM}$ phosphate buffer ( $\mathrm{pH}$ 6.8), $2.5 \mathrm{mM}$ LDOPA and $300 \mu \mathrm{g}$ supernatant protein. After incubating at $37^{\circ} \mathrm{C}$ for $15 \mathrm{~min}$, absorbance was measured at $475 \mathrm{~nm}$ using a microplate reader.

\section{Western blot for tyrosinase, TRP-1 and TRP-2}

Cells were lysed with ice cold lysis buffer containing protease inhibitors and centrifuged at $14,000 \mathrm{rpm}$ for 10 min. The protein content of each supernatant was determined using a Bradford assay with BSA as the protein standard. Samples $(20 \mu \mathrm{g})$ were separated by polyacrylamide gel $(10 \%)$ electrophoresis, and then transferred to polyvinylidene membranes $(0.45 \mu \mathrm{m}$, Millipore, USA). Membranes were blocked with 5\% non-fat dry milk in Tris buffered saline (TBS) containing 0.1\% Tween 20 (TBST) for $1 \mathrm{~h}$. After blocking, membranes were incubated with tyrosinase, TRP-1, TRP-2, and $\beta$-actin (Abcam) in TBST overnight at $4^{\circ} \mathrm{C}$. After washing in TBST, the membranes were incubated with horseradish peroxidaseconjugated secondary antibodies at a dilution of 1:5000 (GE Healthcare Life Science, UK) for $1 \mathrm{~h}$ at room temperature. After washing with TBST, proteins were visualized using an enhanced chemiluminescence detection system. Densitometric analysis was performed using Quantity One (Bio-Rad, Hercules, USA) to scan the signals.

\section{Reverse transcription-polymerase chain reaction (RT-PCR) for tyrosinase, TRP-1 and TRP-2}

Total RNA was isolated using the RNeasy Mini Kit (Qiagen, Germany) according to the manufacturer's instructions. Reverse transcription of total RNA $(1 \mu \mathrm{g})$ was performed using a QuantiTect Reverse Transcription Kit (Qiagen, Germany). The reaction was terminated by heating at $95^{\circ} \mathrm{C}$ for $5 \mathrm{~min}$. cDNA was amplified using a PCR Premix Kit (i-Taq, iNtRON Biotechnology, Korea) for denaturation at $94^{\circ} \mathrm{C}$ for $5 \mathrm{~min} ; 94^{\circ} \mathrm{C}$ for $30 \mathrm{~s}, 5^{\circ} \mathrm{C}$ for 30 $\mathrm{s}$ and $1 \mathrm{~min}$ at $72^{\circ} \mathrm{C}$ for 30 cycles, followed by $10 \mathrm{~min}$ at $72^{\circ} \mathrm{C}$ for elongation using PCR Thermal Cycler Dice (TaKaRa, Japan). The primer sequences were as follows: mouse tyrosinase, 5'-GGCCAGCTTTCAGGCAGAGGT3'(forward) and 5'-TGGTGCTTCATGGGCAAAATC-3' (reverse); mouse TRP-1, 5'-GCTGCAGGAGCCTTCTT
TCTC-3'(forward) and 5'-AAGACGCTGCACTGCTGGTCT-3'(reverse); mouse TRP-2, 5'-GGATGACCGTGA GCAATGGCC-3'(forward) and 5'-CGGTTGTGACCAA TGGGTGCC-3'(reverse), and mouse glyceraldehyde-3phosphate dehydrogenase (GAPDH) as an internal control, 5'-ACCACAGTCCATGCCATCAC-3' (forward) and 5'-TCCACCACCCTGTTGCTGTA-3'(reverse). The PCR products were analyzed by $1.5 \%$ agarose gel electrophoresis with ethidium bromide. The signal intensity of each band was quantified and normalized to the GAPDH signal. Densitometric analysis was performed using Quantity One (Bio-Rad, Hercules, USA) to scan the signals.

\section{Statistical analysis}

All data are expressed as the mean \pm standard error of the mean (SEM). Statistical differences among groups were calculated by analysis of variance followed by Duncan's multiple range test (SPSS Version 18.0, USA). Differences with a $P$ value less than 0.05 were considered significant.

\section{Results}

\section{Effects of WSRJ on cell viability}

The optimal dose from the cell viability assay using MTT in B16F1 melanoma cells are shown in Figure 1. The cell viability was $109 \pm 5.3 \%$ at $1 \mu \mathrm{g} / \mathrm{mL}, 114 \pm 2.0 \%$ at $5 \mu \mathrm{g} / \mathrm{mL}, 110 \pm 4.2 \%$ at $10 \mu \mathrm{g} / \mathrm{mL}, 116 \pm 2.1 \%$ at $50 \mu \mathrm{g} /$ $\mathrm{mL}$ and $109 \pm 8.9 \%$ at $100 \mu \mathrm{g} / \mathrm{mL}$ during a $24 \mathrm{~h}$ treatment. WSRJ clearly was showed the non-cytotoxic to B16F1 melanoma cells.

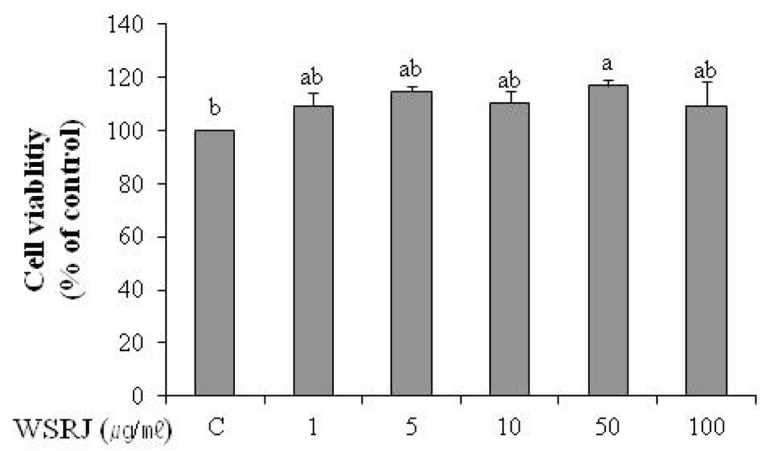

Fig. 1. Cell viability after WSRJ in B16F1 cells. B16F1 cells were treated with $10 \mathrm{nM} \alpha-\mathrm{MSH}$ for $48 \mathrm{~h}$ and then further $24 \mathrm{~h}$ with WSRJ at $1-100 \mathrm{mg} / \mathrm{mL}$. Cell viability was determined by measuring the absorbance at $570 \mathrm{~nm}$ using a microplate reader. Data are presented as mean \pm SEM of five independent experiments. Different letters indicate a significant difference with $p<0.05$. 


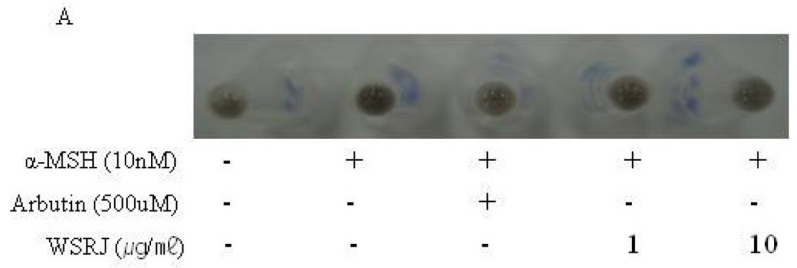

B

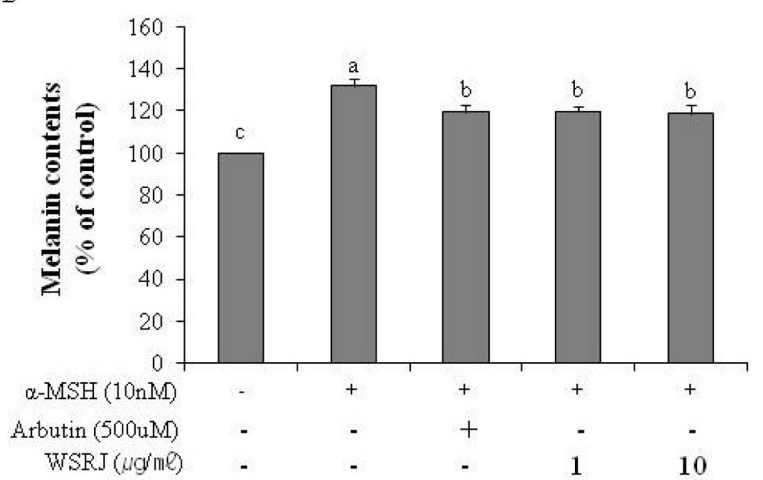

Fig. 2. Inhibitory effect on melanogenesis in B16F1 cells. B16F1 melanoma cells were stimulated with $10 \mathrm{nM} \alpha-\mathrm{MSH}$ for $48 \mathrm{~h}$ and the medium was replaced with fresh medium with or without various concentrations of WSRJ and the cells were incubated for $24 \mathrm{~h}$. (A) Photograph of cell pellets. (B) Synthesized melanin contents. Data are presented as mean \pm SEM of five independent experiments. Different letters indicate a significant difference with $p<0.05$.

\section{Suppression of melanin synthesis by WSRJ}

Arbutin is an effective and well known anti-melanogenesis agent, and was used as a positive control. WSRJ significantly $(p<0.05)$ suppressed $\alpha$-MSH stimulated melanin synthesis compared to that in $\alpha-\mathrm{MSH}$ only treated $\mathrm{B} 16 \mathrm{~F} 1$ melanoma cells, while arbutin also significantly reduced $(p<0.05)$ melanin synthesis (Fig. 2).

\section{Inhibition of tyrosinase activity by WSRJ}

We further evaluated the direct inhibitory action of WSRJ on tyrosinase activity by using mushroom tyrosinase, and measured the absorbance of dopaquinone which is produced by an oxidative reaction with mushroom tyrosinase as the enzyme and L-DOPA as the enzyme substrate. Fig. 3A shows the inhibition of DOPA oxidase activity of mushroom tyrosinase by WSRJ in B16F melanoma cells. At a dose of $10 \mu \mathrm{g} / \mathrm{mL}$, WSRJ reduced mushroom tyrosinase activity by $11 \%$. We then examined the inhibitory effect of WSRJ on cellular tyrosinase activity in $\alpha$-MSH stimulated B16F1 melanoma cells. WSRJ inhibited cellular tyrosinase activity in the crude lysates compared to $\alpha-\mathrm{MSH}$ only treated $\mathrm{B} 16 \mathrm{~F} 1$ melanoma cells (Fig. 3B). As expected, the inhibitory effect of the posi-

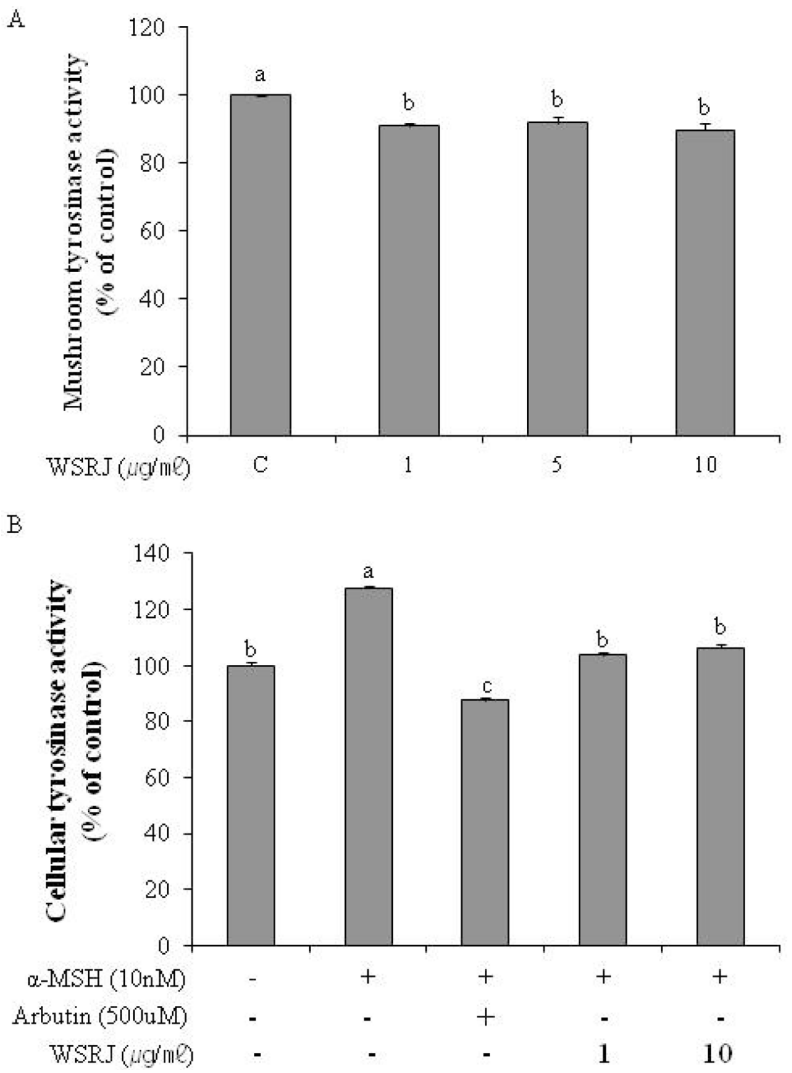

Fig. 3. Inhibitory effect of WSRJ on tyrosinase activity in B16 F1 cells. (A) Tyrosinase activity was determined using mushroom tyrosinase and by measuring the absorbance of dopaquinone that is produced by an oxidative reaction with mushroom tyrosinase as the enzyme and L-DOPA as the enzyme substrate. (B) Cellular tyrosinase activity was measured using B16F1 melanoma cell lysates. Data are presented as mean \pm SEM of five independent experiments. Different letters indicate a significant difference with $p<0.05$.

tive control arbutin on tyrosinase activity was observed. These results indicate that WSRJ suppresses melanin synthesis by directly inhibiting tyrosinase and cellular tyrosinase activity in $\alpha$-MSH stimulated B16F1 melanoma cells.

\section{Suppression of tyrosinase, TRP-1 and TRP-2 pro- tein expression by WSRJ}

The melanogenic enzymes such as tyrosinase, TRP-1 and TRP-2 synthesized the melanin. To investigate whether WSRJ can influence melanogenic protein expression, Western blotting analysis was carried out using the lysate of B16F1 melanoma cells treated with WSRJ and stimulated by either $\alpha$-MSH. When cells were stimulated by $\alpha$ $\mathrm{MSH}$, a significant increase of tyrosinase protein was observed, and TRP-1, 2 expression also increased. As shown in Fig. 4, WSRJ dramatically inhibited tyrosinase, TRP-1 


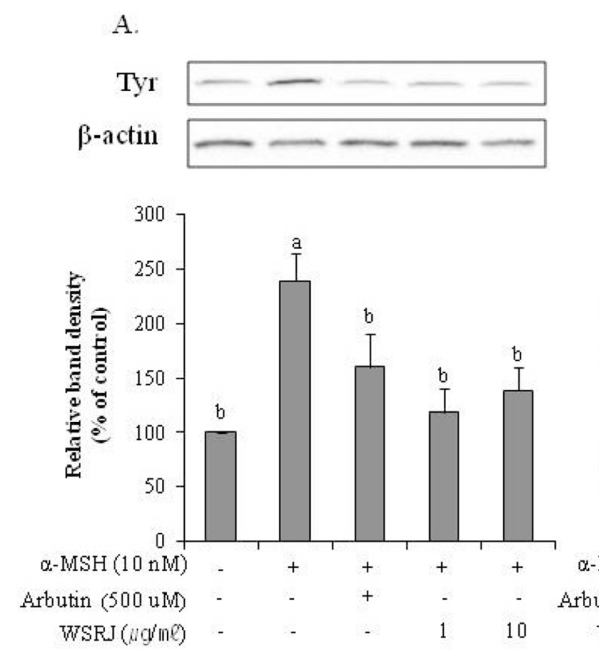

B
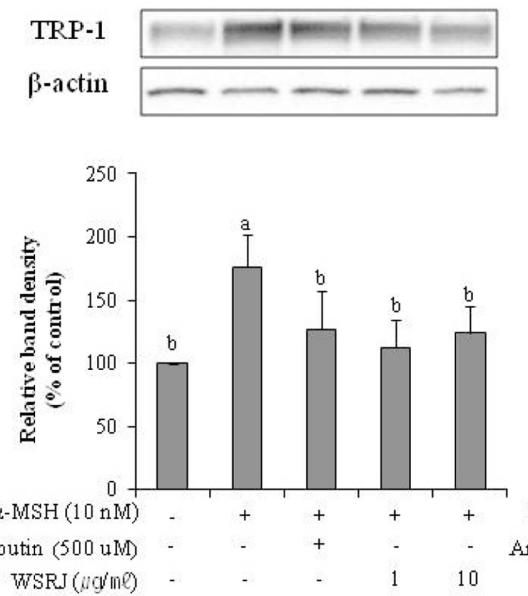

C.
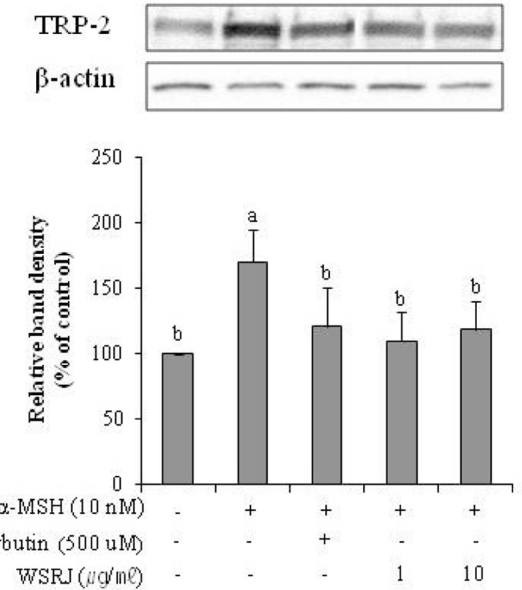

Fig. 4. Suppression of WSRJ on tyrosinase, TRP-1 and TRP-2 protein expression in B16F1 cells. Cells were stimulated with 10 $\mathrm{nM} \alpha$-MSH for $48 \mathrm{~h}$, the medium was replaced with fresh medium with or without various concentrations of WSRJ and the cells were incubated for $24 \mathrm{~h}$. Data are presented as mean \pm SEM of five independent experiments. Western blot analysis of protein for tyrosinase (A), TRP-1 (B), TRP-2 (C) and $\beta$-actin. The relative band intensity of the enzymes was normalized by $\beta$-actin. Different letters indicate a significant difference with $p<0.05$.

and TRP-2 expression in $\alpha$-MSH stimulated B16F1 melanoma cells compared with those of control (approximately $138.7 \%, 76.3 \%$ and $70.0 \%$, respectively, for Fig. $4 \mathrm{~A}$, $\mathrm{B}$ and $\mathrm{C}$ ). WSRJ inhibited the protein expression levels of melanogenic enzymes as similar to those of control and arbutin.

\section{Down regulated tyrosinase, TRP-1 and TRP-2 mRNA expression}

To investigate the effects of WSRJ on melanogenic gene transcription, RT-PCR analysis was carried out. As shown in Figure 5, tyrosinase, TRP-1 and TRP-2 gene expression were significantly $(p<0.05)$ decreased by WSRJ at doses of 1 and $10 \mu \mathrm{g} / \mathrm{mL}$ in $\alpha-\mathrm{MSH}$ stimulated B16F1 melanoma cells compared to those of control (approximately $13.6 \%, 7.7 \%$ and $7.7 \%$, respectively, for Fig. 5A, B and C) similar to protein expression of each enzyme. Arbutin inhibited mRNA expression of melanogenic enzymes at levels similar to those of WSRJ. These findings indicate that downregulation of WSRJ on melanogenesis is due to the decreased levels of melanogenic enzymes, tyrosinase, TRP-1 and TRP-2 proteins and mRNA expression in parallel with the inhibition of tyrosinase activity.

\section{Discussion}

In the present study, we have demonstrated the inhibitory mechanism of WSRJ in B16F1 melanoma cells. WSRJ did not show any cytotoxicity, WSRJ inhibited melanin synthesis in $\alpha$-MSH stimulated B16F1 melanoma cells and directly inhibited tyrosinase activity and cellular tyrosinase activity. Also, WSRJ inhibited the mRNA and protein expression of tyrosinase, TRP- 1 and TRP- 2 in $\alpha-\mathrm{MSH}$ stimulated B16F1 melanoma cells. These results indicate that WSRJ has anti-melanogenic effects through direct inhibition of tyrosinase activity in parallel with the inhibition of melanogenic enzyme activities in $\alpha$-MSH stimulated $\mathrm{B} 16 \mathrm{~F} 1$ melanoma cells. To stimulate melanogenesis, we used cAMP inducers such as $\alpha$-MSH (Imokawa, 2004). $\alpha$-MSH stimulates melanogenesis by binding to MC1R, resulting in an increase of intracellular cAMP (Busca and Ballotti, 2000).

There are three well-known enzymes such as tyrosinase, TRP-1 and TRP-2, and the upregulation of these enzymes results in an increase in melanin synthesis. Melanogenesis is stimulated by ultraviolet light, X-rays, inflammatory cytokines and hormones. Cyclic AMP activates microphthalmia-associated transcription factor, which leads to upregulation of expression of tyrosinase, TRP-1 and TRP-2 consequently resulting in melanin biosynthesis (Ando et al., 1999). In the present study, we did not test the inhibitory of WSRJ on microphthalmia-associated transcription factor expression and cAMP pathway, anti-melanogenic effects of WSRJ might have been mediated through the downregulation of the cAMP pathway by MC1R and adenylate cyclase activation. Furthermore, WSRJ might have inhibited the expression of microphthalmia-associ- 


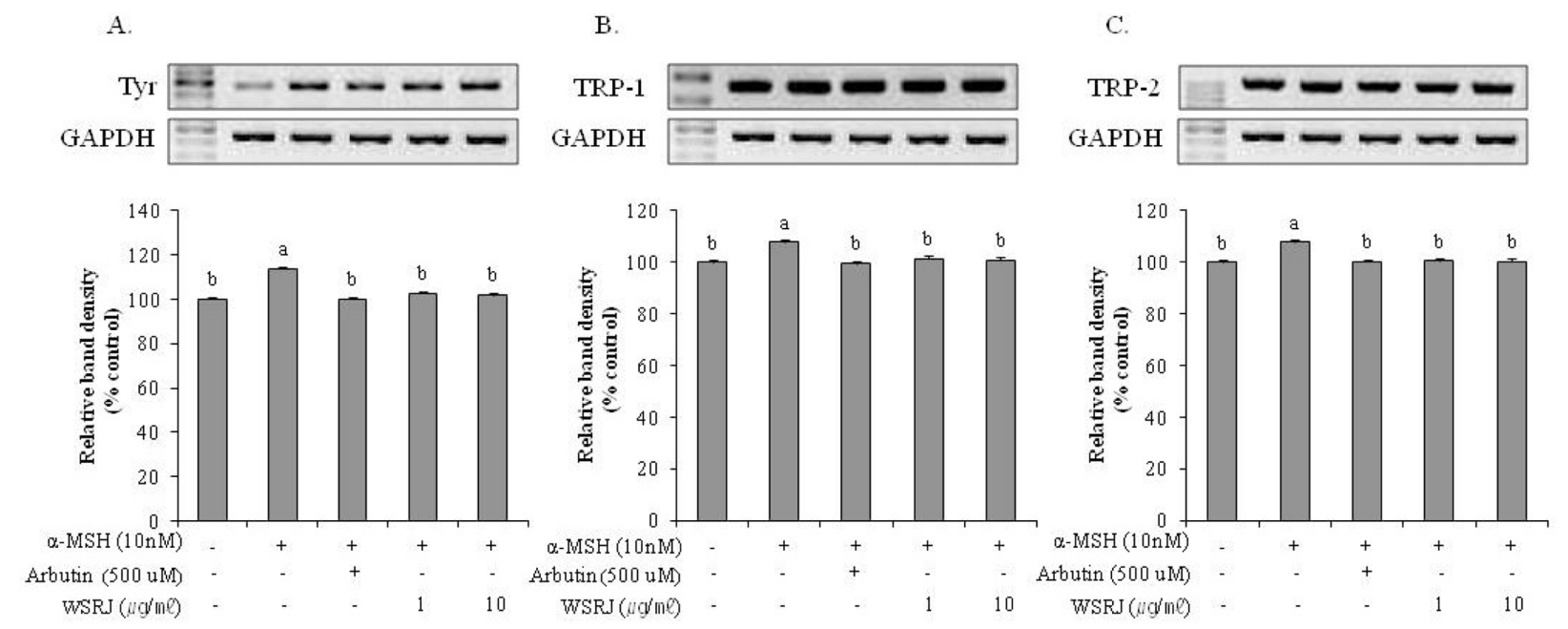

Fig. 5. Down-regulation of WSRJ on tyrosinase, TRP-1 and TRP-2 mRNA expression in B16F1 cells. Cells were stimulated with $10 \mathrm{nM} \alpha$-MSH for $48 \mathrm{~h}$, the medium was replaced with fresh medium with or without various concentrations of WSRJ and the cells were incubated for $24 \mathrm{~h}$. Data are presented as mean \pm SEM of five independent experiments. RT-PCR analysis of mRNA for tyrosinase (A), TRP-1 (B), TRP-2 (C) and GAPDH. The relative band intensity of the enzymes was normalized to GAPDH, and the different letters indicate a significant difference with $p<0.05$.

ated transcription factor, which resulted in the downregulation of tyrosinase, TRP-1 and TRP-2 activity. In fact, pigmentation defects in skin, eyes and hair have been observed in patients suffering from mutations of microphthalmia-associated transcription factor (Barsh, 1996). Thus, WSRJ could provide an element for regulating both mRNA and protein expression of tyrosinase, TRP-1 and TRP-2.

Royal jelly (RJ) is a natural food that contains proteins, carbohydrates, fats, free amino acid, vitamins and minerals. As for its bioactive component, 10-HDA is characterized as the principal unsaturated fatty acid in RJ, indicating that low 10-HDA content implies a low RJ activity. According to our preliminary data, 10-HDA content is over eight times higher in WSRJ than that in RJ, with its content being $60-80 \%$ in the water-soluble fraction of RJ (Kim et al., 2013). Therefore, 10-HDA may also be a major bioactive component of WSRJ. RJ contains various hydroxyl fatty acids, the molecular structures of which are similar to 10-HDA (Lercker et al., 1982) and they are mostly unsaturated fatty acids such as 10-hydrodecanoic acid and 3-hydroxydecanoic acid. Unsaturated fatty acids are reported to decrease melanin synthesis and tyrosinase activity, leading to downregulation of melanogenesis (Koya-Miyata et al., 2004). Although more research is needed to further clarify the mechanisms of the anti-melanogenic effects of WSRJ, we demonstrated the depigmentation effect of WSRJ.

In this report, we demonstrated the depigmentation effect of PQQ. PQQ inhibited cAMP- and IBMX-enhanced mel- anin production in B16 melanoma cells. Our results show that WSRJ inhibits tyrosinase, TRP-1, and TRP-2 gene transcription and subsequent protein. This result implies that WSRJ directly inhibits transcription of tyrosinase, TRP-1, and TRP-2 to produce the inhibition of melanin synthesis in B16F1 melanoma cells. Further studies are necessary to clarify the mechanism of down-regulation. WSRJ is a useful inhibitor of melanogenesis and it might lead to an effective treatment for hyperpigmentation disorders.

\section{Acknowledgements}

This work was carried out with the support of "Cooperative Research Program for Agriculture Science \& Technology Development (Code \#: PJ01083701)" Rural Development Administration, Republic of Korea.

\section{References}

1. Ando, H., Funasaka, Y., Oka, M., Ohashi, A., Furumura, M., Matsunaga, J., Matsunaga, N., Hearing, V. J., and Ichihashi, M. (1999) Possible involvement of proteolytic degradation of tyrosinase in the regulatory effect of fatty acids on melanogenesis. J. Lipid Res. 40, 1312-1316.

2. Barsh, G. S. (1996) The genetics of pigmentation: From fancy genes to complex traits. Trends Genet. 12, 299-305.

3. Buscà, R. and Ballotti, R. (2000) Cyclic AMP a key messenger in the regulation of skin pigmentation. Pigment Cell Res. 13, 60-69. 
4. Chang, T. S. and Chen, C. T. (2012) Inhibitory effect of homochlorcyclizine on melanogenesis in $\alpha$-melanocyte stimulating hormone-stimulated mouse B16 melanoma cells. Arch. Pharm. Res. 35, 119-127.

5. Food and Agriculture Organization of the United Nations (FAO) (2007) Value-added products from beekeeping. http:// www.fao.org/docrep/w0076E/w0076E00.htm.

6. Han, S. M., Yeo, J. H., Cho, Y. H., and Pak, S. C. (2011) Royal jelly reduces melanin synthesis through down-regulation of tyrosinase expression. Am. J. Chin. Med. 39, 1253-1260.

7. Hearing, V. J. (1999) Biochemical control of melanogenesis and melanosomal organization. J. Investig. Dermatol. Symp. Proc. 4, 24-28.

8. Hearing, V. J. and Tsukamoto, K. (1991) Enzymatic control of pigmentation in mammals. FASEP J. 5, 2902-2909.

9. Imokawa, G. (2004) Autocrine and paracrine regulation of melanocytes in human skin and in pigmentary disorders. Pigment Cell Res. 17, 96-110.

10. Jozef, S. (2001) Some properties of the main protein of honeybee (Apis mellifera) royal jelly. Apidologie. 32, 69-80.

11. Kim, J. M., Han, S. M., Cho, M. R., Lee, K. G., Lee, M. L., Lee, M. Y., Woo, S. O., Hong, I. P., Sim, H. S., and Choi, Y. S. (2013) Characterization of water soluble royal jelly removed allergenic protein. Korean J. Apiculture 28, 19-23.

12. Kohno, K., Okamoto, I., Sano, O., Arai, N., Iwaki, K., Ikeda, M., and Kurimoto, M. (2004) Royal jelly inhibits the production of proinflammatory cytokines by activated macrophages. Biosci. Biotechnol. Biochem. 68, 138-145.

13. Koya-Miyata, S., Okamoto, I., Ushio, S., Iwaki, K., Ikeda, M., and Kurimoto, M. (2004) Identification of a collagen production-promoting factor from an extract of royal jelly and its possible mechanism. Biosci. Biotechnol. Biochem. 68, 767-773.

14. Lee, E. H, Lim, Y. J., Ha, S. K., Kang, T. H., Koketsu, M., Kang, C., Kim, S. Y., and Park, J. H. (2010) Inhibitory effects of 5-chloroacetyl-2-piperidino-1,3-selenazole, a novel selenium-containing compound, on skin melanin biosynthesis. $J$. Pharm. Pharmacol. 62, 352-359.

15. Lercker, G., Capella, P., Conte, L. S., Ruini, F., and Giordani, G. (1982) Components of royal jelly II. The lipid fraction, hydrocarbons and sterols. J. Apicultural Res. 21, 178-184.

16. Park, H. M., Cho, M. H., Cho, Y., and Kim, S. Y. (2012) Royal jelly increases collagen production in rat skin after ovariectomy. J. Med. Food 15, 568-575.

17. Park, H. M., Hwang, E. S., Lee, K. G., Han, S. M., Cho, Y. H., and Kim, S. Y. (2011) Royal jelly protects against ultraviolet B-induced photoaging in human skin fibroblast via enhancing collagen production. J. Med. Food 14, 899-906.

18. Rosmilah, M., Shahnaz, M., Patel, G., Lock, J., Rahman, D., Masita, A., and Noormalin, A. (2008) Characterization of major allergens of royal jelly Apis mellifera. Trop. Biomed. 25, 243-251.

19. Solano, F., Briganti, S., Picardo, M., and Ghanem, G. (2006) Hypopigmenting agents: an updated review on biological, chemical and clinical aspects. Pigment Cell Res. 19, 550-571.

20. Tolanai, S. and Morgan, J. F. (1962) Studies on the in vitro antitumor activity of fatty acids. V. Unsaturated acids. Can. J. Biochem. Physiol. 40, 869-875.

21. Tokunaga, K. H., Yoshida, C., Suzuki, K. M., Maruyama, H., Futamura, Y., Araki, Y., and Mishima, S. (2004) Antihypertensive effect of peptides from royal jelly in spontaneously hypertensive rats. Biol. Pharm. Bull. 27, 189-192.

22. Urabe, K., Nakayama, J., and Hori, Y. (1998) The pigmentary system: physiology and pathophysiology. Oxford University Press, New York, pp. 760-766.

23. Yokota, T., Nishio, H., Kubota, Y., and Mizoguchi, M. (1998) The inhibitory effect of glabridin from licorice extracts on melanogenesis and inflammation. Pigment Cell Res. 11, 355361. 